\title{
Economic Implications of Food Demand in Akoko South West, Ondo State, Nigeria: Aids Approach
}

\author{
Edun, Adebisi Temitope* and Adamu Haruna \\ Department of Economics, Adekunle Ajasin University, Akungba-Akoko, Ondo State, Nigeria
}

\begin{abstract}
The study examined the socio-economic characteristics of food consuming households, estimated the complete demand functions for some selected common food commodities, their prices and expenditure elasticities in Akoko South West (ASW) local government in Ondo state, Nigeria. The study examined demand analysis for food in ASW, using primary data with the use of questionnaire on some selected food-consuming households within the study area. Data collected were subjected to descriptive statistics for estimating demographic variables. The result of the descriptive statistics showed that semolina constituted the largest share of the household total food expenditure, among the low income and rural households but mostly among the married and the medium-size male-headed households who had tertiary-education. The Almost Ideal Demand System results showed that besides being a normal good, price inelastic, and expenditure inelastic, semolina has changed from being a luxury to being a necessity and has become a major food staple in the ASW metropolis. In conclusion, the study discovered that the prices of rice, beans, yam, garri, wheat, yam flour, and semolina were significantly important in the share of household total food budget at constant real income. Finally, the study showed from the result that the importance of semolina in ASW metropolis diet will increase as economic growth continues. This study therefore recommends that effort should be made to boost economic activities of ASW zone. This will increase their income and consequently improve their spending on the nutritious food items.
\end{abstract}

Key Words: Demand System, expenditure elasticities, cross-price elasticities, food commodity groups, demand pattern, demographic effects, compensated elasticities

\section{Introduction}

Demand for food is an important area of study for economists of all ages. According to Koutsoyiannis (1982), the traditional study of demand is focused mainly on the price of the commodity ( $\mathrm{P} 0)$, the price of other commodity (P1), income of consumers (I), and tastes (T). The highlighted factors shows that demand pattern for food in Akoko South West (ASW) can be analyze and classified through the tools in simulation of income and prices for foods consumed by various consumers in the markets. The use of Almost Ideal Demand System (AIDS) will be assessed in view of estimating the demand for food making provisions for changes in income during past and present price shocks due to changes in government policies.

Akoko South West is a local government area with the composition of about four small towns, Akungba, Oba, Oka, and Supare (sub-groups of Yoruba speaking people in Nigeria), with the headquarters in the town of Oka (Akoko). ASW is predominantly situated in rocky areas of Ondo state,

\footnotetext{
${ }^{*}$ Corresponding author.
}

the rock terrain nevertheless, as helped the region to become a melting pot of sorts among the other local governments in the state. It has an area of $530 \mathrm{~km}^{2}$ and a population of 229,486 at the 2006 census (Wikipedia 2013). Its residence and visitors are predominantly involved in tradition and modern occupation like farming, teaching, business (banking, cyber café, and trading of all sorts of industrial goods) and with recent development of establishing a tertiary institution (Adekunle Ajasin University) in one of the towns-Akungba, more jobs are created and this has improved the economic welfare of the people in the local government as the marginal propensity to consume increase and the demand for commodities increase over time in the area.

Since the inception of AIDS by Angus Deaton and John Muellbauer, a demand system of linear function of expenditure is known as an exactly agreeable demand system because the same type of equation can be used for aggregate data as well as for micro data. AIDS is one of the most popular demand systems (Bereket, 2003).

Agriculture remains the most important sector of the economy, and the role of agriculture cannot be over emphasized given its importance in the life of 
human beings in the area under study. Agriculture is expected to ensure adequate supply of food to the people, however, it is disheartening to know that economic deregulation in Nigeria as a whole recently brought about a reduction in household income levels and this affect the livelihood pattern including food consumption of most rural household which have remain deplorable, ASW inclusive. The production of major foods in Nigeria has not been sufficient to satisfy the demand of an increasing population and do not provide a balanced diet, as such, malnutrition is prevalent in most homes. This has led to massive importation of food and massive foreign debts (CBN 1996) at the national level. Food remains a basic need for human existence and major source of nutrient needed to run the day activities, hence, the need for its availability and accessibility (USAID, 1992). Thus, it becomes imperative to analyze the demand patter of food in Akoko South West.

The main objectives of this study are to: evaluate the demand pattern of food item, examine the socioeconomic character of food demand in ASW using the AIDS model and analyze the determinants of food demand among households in ASW.

\section{Theoretical and Empirical Framework}

Almost Ideal Demand System (AIDS) is consistent with the theoretical elasticity and consumer theory which requires general restrictions (Deaton \& Muellbauer 1980). Also, various authors have estimated demand for food, meat, and consumable products in the past.

Blanciforti and Green (1986) explain the basic two approaches to estimate demand systems. The first approach starts with a utility function that satisfies certain axioms of choice. Demand functions are obtained by maximizing the utility function subject to budget constraints. The majority of demand functions estimated towards the focus area of concern used this approach. The second one starts with an arbitrary demand system and then imposes restriction on the system. This approach corresponds with macro and micro economics theories to a much closer extent than the first approach and it's therefore the method applied in various studies over the past years.

The popularity of the AIDS can be ascribed to several reasons according to Deaton and Muellbauer (1980); Alston and Chalfant (1993). Firstly, the linear approximate version of the AIDS is relatively easy to estimate and interpret. It satisfies the axiom of choice exactly. Secondly, it is as flexible as other locally flexible functional forms, but it has the added advantage of being compatible with allegation over consumers. Thus, it can be interpreted in terms of economic models of consumer behavior when estimated with aggregate (macro-economics) or disaggregated (household survey) data (Glewwe, 2005). Thirdly, it is derived from a specific cost function and therefore corresponds with a welldefined preference structure, which is convenient for welfare analysis. Fourthly, homogeneity and symmetry restrictions depend only on the estimated parameters and are therefore easily tested and/or imposed. Fifthly, AIDS provides an arbitrary first order approximation to any demand systems. Sixthly, it aggregate perfectly across consumers without invoking parallel linear Engel curve, and finally, it has a functional form which is consistent with known household budget data.

Halbrendt et al (1994) and Fan et al (1995) applied the AIDS model to analyze the household pattern in china. The two studies found that the lowest expenditure elasticities are found in grain. Halbrendt used a few luxurious food products in the study, the highest expenditure elasticities was calculated for fruits. The major difference in the two studies' empirical findings is in the values of food expenditure elasticities which suggest that a massive number of food products are necessary goods. This could be ascribed to the facts that different sampling techniques and data set were employed in the two studies.

Blanciforti and Green (1986) using annual time series data from 1948-78 for United State of America analyzed four food groups with AIDS. He compared the estimates of linear approximation version of AIDS and the Linear Expenditure System (LES). He focused on comparing three models for four food groups; meat, fruits and vegetables, cereals and bakery production and miscellaneous foods. $\mathrm{He}$ concluded that the estimated expenditure elasticity's between the AIDS and the LES differ greatly.

Baharumshah and Mohamed (1993) using the linear approximate version of AIDS examined the demand for all meat products and obtained high expenditure elasticity of demand for poultry, mutton, pork, fish and beef. Ishida et al (2003), using only West Malaysia data affirmed that the changing pattern in food consumption among the Malaysians was highly attributed to the population growth, rapid urbanization and a higher per-capital income that led to the drastic change in Malaysian lifestyle.

According to Oyekale (2000) food calorie among Nigerian household has been found to have a strong empirical linkage with both human health productivity and thus determine the influence of income changes and price on the availability of nutrient. He found guinea corn as the food with the highest nutrient status for low income status. He 
concluded that the major items for average and high income status are guinea corn, rice, millet, beans and maize.

In his study, Adejobi analyzed the relationship between the demand structure of rural household of food pattern and poverty. His study revealed that $72.0 \%$ of household total expenditure was on food and from which $56.0 \%$ was for cereals, $22.0 \%$ for animal protein, $7.0 \%$ for fruits, $5.0 \%$ for vegetables, $5 \%$ for legumes, $4 \%$ for roots and tubers and $1.0 \%$ for fat and oil and other food items, Adejobi (2004).

\section{Methodology}

The goal of demand analysis is to model households' expenditure patterns elasticity's and to estimate consumer welfare. This study employed the classic model of Deaton and Muellbauer (1980) where demand systems are specified with expenditure shares as the dependent variables. A household's expenditure share for good $\mathrm{j}$ is defined as:

$\Omega_{\mathrm{j}=} \mathrm{p}_{\mathrm{j}} \mathrm{q}_{\mathrm{j}} / \mathrm{m}$

Where $p_{j}$ is the price paid for good $j, q_{j}$ is the quantity of good $\mathrm{j}$ purchased or consumed by the household and $\mathrm{m}$ is the total expenditure on all goods in the demand system. With $\mathrm{m}$ defined as,

$$
\sum_{n=1}^{k=}
$$

Where $\mathrm{k}$ is the number of goods in the system.

This study ensures an effective appraisal of food demand in Akoko South-West (ASW), using an Almost Ideal Demand System (AIDS). A questionnaire based interview is used for sampling the perception of consumers towards food demand in the market under study. The data gathered consist of spending, prices of different food commodities, per capital consumption of staple and non-staple foods in ASW. The questionnaire was classified into two sections. Section A focused on personal data and gave brief information of the respondents' background while section B focused on collection of relevant information on food prices, commodities consumed by consumers and the income spent on each commodity. The data gathered was analyzed using STATA software package version 11 for windows.

\section{Model Specification}

The expenditure share equation for the AIDS model is expressed as follows:

$$
\Omega_{\mathrm{j}}=\tau_{\mathrm{j}}+\Sigma \lambda_{\mathrm{ji}} \ln p_{\mathrm{j}}+\eta_{\mathrm{j}} \ln (\mathrm{G} / \mathrm{P})
$$

The explicit form of the budget share is presented as

$$
\begin{aligned}
& \Omega_{1=} \tau_{11+} \lambda_{11} \operatorname{lnp}{ }_{1+} \lambda_{12} \operatorname{lnp}_{2+} \lambda_{13} \operatorname{lnp}_{3+} \lambda_{14} \operatorname{lnp}_{4+} \lambda_{15} \operatorname{lnp}_{5+} \lambda_{16} \operatorname{lnp}_{6+} \lambda_{17} \operatorname{lnp}_{7+} \lambda_{18} \operatorname{lnp} p_{8+} \eta_{1} \ln (\mathrm{GO} / \mathrm{P}) \\
& \Omega_{2}=\tau_{21+} \lambda_{21} \ln p_{1+} \lambda_{22} \ln p_{2+} \lambda_{23} \operatorname{lnp} p_{3+} \lambda_{24} \ln p_{4+} \lambda_{25} \operatorname{lnp} p_{5+} \lambda_{26} \ln p_{6+} \lambda_{27} \ln p_{7+} \lambda_{28} \ln p_{8}+\eta_{2} \ln (\mathrm{G} / \mathrm{P}) \\
& \Omega_{3=} \tau_{31+} \lambda_{31} \operatorname{lnp}_{1+} \lambda_{32} \operatorname{lnp}_{2+} \lambda_{33} \operatorname{lnp}_{3+} \lambda_{34} \operatorname{lnp}_{4+} \lambda_{35} \operatorname{lnp}{ }_{5+} \lambda_{36} \operatorname{lnp}_{6+} \lambda_{37} \operatorname{lnp}{ }_{7+} \lambda_{38} \operatorname{lnp} p_{8+} \eta_{3} \ln (\mathrm{GO} / \mathrm{P}) \\
& \Omega_{4}=\tau_{41+} \lambda_{41} \operatorname{lnp}{ }_{1+} \lambda_{42} \operatorname{lnp}_{2+} \lambda_{43} \operatorname{lnp}_{3+} \lambda_{44} \operatorname{lnp}{ }_{4+} \lambda_{45} \operatorname{lnp}{ }_{5+} \lambda_{46} \operatorname{lnp}_{6+} \lambda_{47} \operatorname{lnp}{ }_{7+} \lambda_{48} \operatorname{lnp} p_{8} \eta_{4} \ln (\mathrm{GO} / \mathrm{P}) \\
& \Omega_{5}=\tau_{51+} \lambda_{51} \operatorname{lnp}{ }_{1+} \lambda_{52} \operatorname{lnp}_{2+} \lambda_{53} \operatorname{lnp}_{3+} \lambda_{54} \operatorname{lnp}_{4+} \lambda_{55} \operatorname{lnp}_{5+} \lambda_{56} \operatorname{lnp} p_{6+} \lambda_{57} \operatorname{lnp}{ }_{7+} \lambda_{58} \operatorname{lnp}{ }_{8+} \eta_{5} \ln (\mathrm{GO} / \mathrm{P}) \\
& \Omega_{6}=\tau_{61+} \lambda_{61} \operatorname{lnp}{ }_{1+} \lambda_{62} \operatorname{lnp}_{2+} \lambda_{63} \operatorname{lnp}{ }_{3+} \lambda_{64} \operatorname{lnp} p_{4+} \lambda_{65} \operatorname{lnp} p_{5+} \lambda_{66} \operatorname{lnp} p_{6+} \lambda_{67} \operatorname{lnp} p_{7+} \lambda_{68} \operatorname{lnp} p_{8+} \eta_{6} \ln (\mathrm{GO} / \mathrm{P}) \\
& \Omega_{7=} \tau_{71+} \lambda_{71} \operatorname{lnp}_{1+} \lambda_{72} \operatorname{lnp}_{2+} \lambda_{73} \operatorname{lnp}_{3+} \lambda_{74} \operatorname{lnp}_{4+} \lambda_{75} \operatorname{lnp}_{5+} \lambda_{76} \operatorname{lnp}{ }_{6+} \lambda_{77} \ln p_{7+} \lambda_{78} \operatorname{lnp} p_{8+} \eta_{7} \ln (\mathrm{G} / \mathrm{P}) \\
& { }_{8}=\tau_{81} \lambda_{81} \operatorname{lnp}_{1+} \lambda_{82} \operatorname{lnp}_{2+} \lambda_{83} \operatorname{lnp}{ }_{3+} \lambda_{84} \operatorname{lnp}_{4+} \lambda_{85} \operatorname{lnp}_{5+} \lambda_{86} \operatorname{lnp}_{6+} \lambda_{87} \ln p_{7+} \lambda_{88} \ln p_{8+} \eta_{8} \ln (\mathrm{GO} / \mathrm{P}) \ldots . .(2)
\end{aligned}
$$


Where:

p1-p8 $=$ Scaled up market prices of rice, beans, garri, wheat, yam, yam flour (elubo), poundo flour and semolina respectively

$\tau=$ The constant coefficient in the share equation representing the value of the budget share in the absence of income and price effects

$\lambda=$ The budget share of the commodity

$\Omega=$ The price coefficients or the slope coefficient associated with any commodity in any other commodity's share equation

$\eta=$ The expenditure coefficient of commodity

$\mathrm{GD}=$ The total expenditure on all commodities

$\mathrm{P}=$ The price index defined as

The theoretical properties are subject to the following constraints:

of adding up, homogeneity in prices and income and symmetry of cross effects of demand functions are subject to the following parametric restrictions:

$$
\begin{array}{lc}
\text { Adding up } & \Sigma \tau \mathrm{j}=1 ; \\
& \Sigma \lambda \mathrm{ji}=0 ; \\
& \Sigma \eta \mathrm{j}=0 \ldots \\
\text { Homogeneity } & \Sigma \lambda \mathrm{ij}=0 \\
\text { Symmetry } & \lambda \mathrm{ij}=\lambda \mathrm{ji}
\end{array}
$$

This study focuses on estimating demand system for food and food products (staple and non-staple). Therefore, the effect of economic and demographic variables on demand for food and food product will be examined. A stone price index suggested by Deaton and Muellbauer (1980) is considered in the function to effectively include demographic variables through either translation or scaling methods (Sadoulet \& de Janvry, 1995).

$\ln \boldsymbol{P}=\Sigma \Omega_{\mathrm{j}} \ln \mathrm{j}_{\mathrm{j}}$

The translation approach is more appropriate to model demographic effect for consumables. Also, the stone price index improves the linear approximation of the model where prices are engaged. We therefore re-specify he equation as:

$\tau_{\mathrm{j}}=\tau_{0}+\Sigma \tau_{\mathrm{ji}} \mathrm{D}_{\mathrm{i}}$

Where $D_{i}$ is the ith demographic variable

The extended model including demographic variable and error term $\left(v_{\mathrm{j}}\right)$ is defined as:

$\Omega_{\mathrm{j}}=\tau_{0}+\Sigma \tau_{\mathrm{ji}} \mathrm{D}_{\mathrm{i}}+\Sigma \lambda_{\mathrm{ji}} \ln p_{\mathrm{j}}+\eta_{\mathrm{j}} \ln (\mathrm{G} / \mathrm{P})+\mathrm{v}_{\mathrm{j}}$

We simultaneously estimate the budget share equations as a system of equations using STATA version 11 software package.

The price and expenditure elasticities were derived from the parameter estimates of the model using the following formula:

$\Sigma_{\mathrm{ij}}=-1+\left(\lambda_{\mathrm{jij}} / \Omega_{\mathrm{j}}\right)-\eta \ldots \ldots \ldots \ldots$ (6) Own-price elasticity $\left.\Sigma_{\mathrm{ji}}=\left(\lambda / \Omega_{\mathrm{j}}\right)-\eta_{\mathrm{j}} \Omega_{\mathrm{i}} / \Omega_{\mathrm{j}}\right) \mathrm{j}$ for $\mathrm{j}$ not equal to i...(7) Crossprice elasticity

$\Sigma_{\mathrm{j}} / \lambda=1+\left(\mathrm{p}_{\mathrm{j}} / \Omega_{\mathrm{j}}\right) \ldots \ldots \ldots \ldots \ldots . . . . . . .(8)$ Expenditure elasticity

\section{Analyses and Interpretation of Results}

A descriptive statistics of respondent responses for the study (reported in table 1) examines the relationship between demand for food in ASW and the demographic variables. The variables of interest include age, status, sex, occupation and education.

Table 1. Demographic variables: descriptive statistics.

\begin{tabular}{llllllll}
\hline Variables & $\mathrm{N}$ & Range & Minimum & Maximum & Sum & Mean & Std. Deviation \\
\hline Age & 300 & 5 & 1 & 6 & 307 & 2.05 & 0.708 \\
Status & 300 & 2 & 0 & 2 & 287 & 1.42 & 0.600 \\
Sex & 300 & 2 & 0 & 2 & 319 & 1.51 & 0.612 \\
Occupation & 300 & 4 & 1 & 5 & 565 & 2.85 & 0.962 \\
Education & 300 & 5 & 0 & 5 & 798 & 4.14 & 0.985 \\
\hline
\end{tabular}

The standard deviation for age, status, sex, occupation and education (demographic variables) are at $0.708,0.600,0.612,0.962$ and 0.985 respectively. The result shows that marital status has the least standard deviation for the selected demographic variables in this study. The mean values of the variables are $2.05,1.42,1.51,2.85$ and 4.14 respectively. The minimum and maximum values for the variables vary between 1 and 6, 0 and 2, 0 and 2, 1 and 5 and 0 and 5 respectively.

The AIDS results presented in table 2 show that the coefficients of $\tau_{1}(-0.0402)$ and $\eta_{1}(-0.0617), \tau_{8}(-$
$0.2347)$ and $\eta_{8}(-0.0713)$ are positively related since they carry negative signs. To show that there is direct relationship between the estimated parameters in the model for the household expenditure and the demand for food item in ASW, as the demand for food item also increases by $17 \%, 2.3 \%, 3.5 \%, 63 \%, 18 \%$ and $35 \%$, the household expenditure also increases by $2.2 \%, 1.3 \%, 0.1 \%, 14 \%, 4.1 \%$ and $6.8 \%$, respectively at $\tau_{2}(0.1703), \tau_{3}(0.0231), \tau_{4}(0.0348), \tau_{5}(0.6347), \tau_{6}$ $(0.1845), \tau_{7}(0.3515)$ and $\eta_{2}(0.0222), \eta_{3}(0.0131), \eta_{4}$ (0.0010), $\eta_{5}(0.1375), \quad \eta_{6}(0.0413), \quad \eta_{7} \quad(0.0684)$ respectively. 
Table 2. Almost ideal demand system results.

\begin{tabular}{|c|c|c|c|}
\hline Parameters & Coef & Std.Err & $95 \%$ Interval \\
\hline$\tau_{1}$ & -0.0402 & -0.0038 & -0.0272 \\
\hline$\tau_{2}$ & 0.1703 & 0.0576 & -0.0101 \\
\hline$\tau_{3}$ & 0.0231 & 0.0034 & -0.0149 \\
\hline$\tau_{4}$ & 0.0348 & 0.0074 & -0.0145 \\
\hline$\tau_{5}$ & 0.6347 & 0.0368 & 0.0397 \\
\hline$\tau_{6}$ & 0.1845 & 0.0016 & 0.0158 \\
\hline$\tau_{7}$ & 0.3515 & 0.2530 & 0.1051 \\
\hline$\tau_{8}$ & -0.2347 & -0.0279 & -0.0357 \\
\hline$\eta_{1}$ & -0.0617 & -0.0022 & -0.0125 \\
\hline$\eta_{2}$ & 0.0222 & 0.2168 & -0.0270 \\
\hline$\eta_{3}$ & -0.0131 & -0.0054 & -0.0400 \\
\hline$\eta_{4}$ & 0.0010 & 0.0003 & -0.0481 \\
\hline$\eta_{5}$ & 0.1375 & 0.0386 & 0.0588 \\
\hline$\eta_{6}$ & 0.0413 & 0.0139 & 0.0010 \\
\hline$\eta_{7}$ & 0.0684 & 0.0299 & 0.0010 \\
\hline$\eta_{8}$ & -0.0713 & -0.0125 & -0.0105 \\
\hline$\lambda_{1 \_1}$ & 0.1426 & 0.0382 & 0.0430 \\
\hline$\lambda_{2 \_1}$ & -0.0579 & -0.0111 & -0.0086 \\
\hline$\lambda_{3-1}^{2}$ & 0.0226 & 0.0101 & -0.0041 \\
\hline$\lambda_{4 \_1}$ & -0.0111 & -0.0030 & -0.0374 \\
\hline$\lambda_{5 \_1}$ & -0.0084 & -0.0008 & -0.0521 \\
\hline$\lambda_{6 \_1}$ & -0.0176 & -0.0072 & -0.0406 \\
\hline$\lambda_{7 \_1}$ & 0.0473 & 0.0126 & 0.0158 \\
\hline$\lambda_{8 \_1}$ & 0.0065 & 0.0028 & -0.0220 \\
\hline$\lambda_{2 \_}$ & 0.1371 & 0.0300 & 0.0107 \\
\hline$\lambda_{3 \_2}$ & 0.0159 & 0.0012 & -0.0067 \\
\hline$\lambda_{4 \_2}$ & 0.0093 & 0.0010 & -0.0132 \\
\hline$\lambda_{5 \_2}$ & -0.0081 & -0.0019 & -0.0541 \\
\hline$\lambda_{6 \_2}$ & -0.0107 & -0.0029 & 0.0229 \\
\hline$\lambda_{7 \_2}$ & -0.0122 & -0.0043 & -0.0338 \\
\hline$\lambda_{8 \_2}$ & -0.0019 & -0.0001 & -0.0270 \\
\hline$\lambda_{3 \_3}$ & 0.1088 & 0.0226 & 0.0252 \\
\hline$\lambda_{4 \_3}$ & 0.0171 & 0.0077 & -0.0068 \\
\hline$\lambda_{5 \_3}$ & 0.0222 & 0.0106 & -0.0113 \\
\hline$\lambda_{6 \_3}$ & -0.0224 & -0.0063 & -0.0435 \\
\hline$\lambda_{7 \_3}$ & -0.0180 & -0.0076 & -0.0418 \\
\hline$\lambda_{8 \_3}$ & -0.0222 & -0.0081 & -0.0469 \\
\hline$\lambda_{4 \_4}$ & 0.1240 & 0.0227 & 0.0503 \\
\hline$\lambda_{5 \_4}$ & 0.0023 & 0.0004 & -0.0329 \\
\hline$\lambda_{6 \_4}$ & -0.0100 & -0.0018 & -0.0302 \\
\hline$\lambda_{7 \_4}$ & -0.0282 & -0.0012 & -0.0521 \\
\hline$\lambda_{8 \_4}$ & 0.0206 & 0.0095 & -0.0048 \\
\hline$\lambda_{5 \_5}$ & 0.1464 & 0.0610 & 0.0471 \\
\hline$\lambda_{6 \_5}$ & 0.0014 & 0.0004 & -0.0287 \\
\hline$\lambda_{7 \_5}$ & 0.0350 & 0.0165 & -0.0061 \\
\hline$\lambda_{8 \_5}$ & -0.0669 & -0.0128 & -0.1007 \\
\hline$\lambda_{6 \_6}$ & 0.1302 & 0.0269 & 0.0106 \\
\hline$\lambda_{7 \_6}$ & -0.0022 & -0.0009 & -0.0225 \\
\hline$\lambda_{8 \_6}$ & 0.0029 & 0.0013 & -0.0186 \\
\hline$\lambda_{7 \_7}$ & 0.1053 & 0.0095 & 0.0068 \\
\hline$\lambda_{8 \_7}$ & -0.0031 & -0.0013 & -0.0313 \\
\hline$\lambda_{88}^{-1}$ & 0.1880 & 0.0309 & 0.0156 \\
\hline
\end{tabular}


The standard errors are $-0.0038,0.0576,0.0034$, $0.0074,0.0368,0.0016,0.2530$ and -0.0279 for $S\left(\tau_{1}\right)$, $S\left(\tau_{2}\right), S\left(\tau_{3}\right)$ and $S\left(\tau_{4}\right), S\left(\tau_{5}\right), S\left(\tau_{6}\right), S\left(\tau_{7}\right)$ and $S\left(\tau_{8}\right)$ respectively. When compared half of each coefficient with its standard error, it was found that $0.0038<0.0402 / 2,0.0576<0.1703 / 2,0.0034<0.0231 / 2$, $0.0074<0.0348 / 2,0.0368<0.6347 / 2,0.0016<0.1845 / 2$ and $0.0279<0.2347 / 2$ for $\tau_{1}, \tau_{2}, \tau_{3}, \tau_{4}, \tau_{5}, \tau_{6}$ and $\tau_{8}$ respectively and for $\tau_{7}, 0.2530>0.3515 / 2$. This shows that the estimated values for $\tau_{1}, \tau_{2}, \tau_{3}, \tau_{4}, \tau_{5}, \tau_{6}$ and $\tau_{8}$ are statistically significant while $\tau_{7}$ is not statistically significant. The implication of this is that demand pattern of rice, beans, garri, wheat, yam, yam flour (elubo) and semolina in respect to household expenditure are statistically significant while even though negative relationship exists between demand pattern of food items consumption in respect to household expenditure, poundo flour do not contribute significantly to the long run pattern of food demand in ASW, Nigeria.

In conjunction with the demographic variables, the relative prices are statistically significant except two out of thirty-six. This shows that a total change in price leads to same change in expenditure share of household for each food commodity which means there is higher quantity response to movement in relative prices.

With the AIDS model, expenditure elasticity values are measured for every estimated parameter value. Table 3 reveals that price elasticities are inelastic for commodity group $\mathrm{G}_{1}, \mathrm{G}_{3}, \mathrm{G}_{4}$, and $\mathrm{G}_{8}$, that is, demand is not elastic and that commodity group $\mathrm{G}_{5}, \mathrm{G}_{6}$ and $\mathrm{G}_{7}$ are elastic. All the price elasticities are positive except for only one food commodity (semolina) which is negative. This means that a $1 \%$ increase in the prices of $G_{1}, G_{2}, G_{3}, G_{4}, G_{5}$, $\mathrm{G}_{6}$, and $\mathrm{G}_{7}$ makes demand grow by $63.03 \%$; $104.49 \%, 72.41 \%$; $83.86 \% ; 178.55 \% ; 126.42 \%$; and $146.51 \%$ respectively while a $1 \%$ increase in the prices of $\mathrm{G}_{7}$ reduces demand by $7.34 \%$. The lowest and the highest price demand elasticities were observed in $\mathrm{G}_{8}, 7.34$ and $\mathrm{G}_{5}, 178.55$ respectively. This means that consumers are more responsive to price changes in $\mathrm{G}_{5}$, and less responsive to price changes in $\mathrm{G}_{8}$. These findings are consistent with economic theory, that is, consumers in $\mathrm{G}_{5}$ are more sensitive than consumers in $\mathrm{G}_{8}$ category.

Table 3. Distribution of expenditure elaticities for food commodity groups.

\begin{tabular}{lllllllll}
\hline $\begin{array}{l}\text { Food } \\
\text { Commodity }\end{array}$ & Rice $\mathrm{G}_{1}$ & Beans $\mathrm{G}_{2}$ & ${\text { Garri } \mathrm{G}_{3}}$ & Wheat $\mathrm{G}_{4}$ & Yam G $_{5}$ & Yam fl G & Poundo fl G & Semolina \\
\hline Expenditure & 0.6303 & 1.0449 & 0.7241 & 0.8386 & 1.7855 & 1.2642 & 1.4651 & -0.0734 \\
Elasticity & Inelastic & Unitary & Inelastic & Inelastic & Elastic & Elastic & Elastic & Inelastic \\
\hline
\end{tabular}

Table 4. Compensated elasticities of food commodity group (AIDS Model).

\begin{tabular}{ccccccccc}
\hline $\mathrm{rlc}$ & Rice $\mathrm{G}_{1}$ & Beans $\mathrm{G}_{2}$ & ${\text { Garri } \mathrm{G}_{3}}$ & Wheat $\mathrm{G}_{4}$ & ${\text { Yam } \mathrm{G}_{5}}$ & Yam fl $\mathrm{G}_{6}$ & Poundo fl $_{7}$ & ${\text { Semolina } \mathrm{G}_{8}}$ \\
\hline $\mathrm{r}_{1}$ & -0.2836 & -0.1931 & 0.1006 & -0.0566 & 0.2007 & -0.0272 & 0.3351 & -0.0750 \\
$\mathrm{r}_{2}$ & -0.2698 & -0.0380 & 0.1113 & 0.0511 & -0.0216 & 0.2688 & -0.0801 & -0.0216 \\
$\mathrm{r}_{3}$ & 0.2025 & 0.1603 & -0.0261 & 0.0915 & 0.3388 & -0.2427 & -0.1573 & -0.3669 \\
$\mathrm{r}_{4}$ & -0.1308 & 0.0848 & 0.1056 & 0.2859 & 0.0783 & -0.1709 & -0.3412 & 0.0883 \\
$\mathrm{r}_{5}$ & 0.2695 & -0.0209 & 0.2265 & 0.0458 & -0.3411 & -0.0649 & 0.0926 & -0.2074 \\
$\mathrm{r}_{6}$ & -0.0585 & 0.4120 & -0.2585 & -0.1578 & -0.1033 & 0.2495 & -0.1170 & 0.0333 \\
$\mathrm{r}_{7}$ & 0.6155 & -0.1054 & -0.1436 & -0.2701 & 0.1265 & -0.1004 & -0.1833 & 0.0607 \\
$\mathrm{r}_{8}$ & -0.1952 & -0.0399 & -0.4704 & 0.0977 & -0.3979 & 0.0403 & 0.0852 & 0.8802 \\
\hline
\end{tabular}

The cross-price elasticities are reported in table 4. The table shows that compensated own price elasticities of all eight food commodity are relatively inelastic. All the cross-price elasticities are statistically significant and carry positive signs as expected for substitute products except for the crossprice elasticity between wheat demand and rice price, and vice versa. The consumption of semolina shows the strongest substitution response for the price of rice $(0.61)$, whereas the consumption of rice is not as responsive to the price of semolina (0.88). The second strongest substitute response is the consumption of beans for the price of yam (0.33), followed by poundo flour for wheat $(0.28)$ and garri for rice (0.11). All the other cross-price elasticities are less than 0.1. This implies that the demand for most food items is most inelastic and that any increase in expenditure of rice especially will not significantly affect the consumption of rice in ASW, Nigeria. 


\section{Conclusion and Recommendation}

This study analyses the demand pattern of food in Akoko South West as the demand for semolina, the pattern of the semolina's expenditure is perfectly inelastic in ASW. Thus, semolina constitutes the largest share of the household total food expenditure in ASW metropolis whilst income does not have much weight in its consumption with less substitutability in response to changes in own-price.

The analyses of the study show that semolina has the highest budget share and average budget share among the food commodities. This implies that a substantial price decline with increased production will benefit the majority of households. Also, Semolina demand is not quite responsive to changes in own-price income, expenditure and household demographics such as household size, sex of household, average age of household, average education and occupation. For any food policy to be effective towards alleviating the problems of food insecurity and malnutrition, attention must be paid to these factors.

More so, Semolina was inelastic with respect to its own price and expenditure on food. This implies that, in general, income-oriented policies will have a greater effect on semolina consumption than price related policies. However, policy should be targeted at reducing the price of semolina particularly for the low-income households who still consider food as a means of surviving rather than an end of consumption.

Furthermore, Semolina constitutes the largest share of the household total food expenditure in ASW while income does not have much weight in its consumption with less substitutability in response to changes in own-price. Semolina has changed from being a luxury to being a necessity and has become a major food staple in ASW metropolis and Ondo state as whole. This implies that policies towards increased semolina production and productivity have significant effect on the availability, affordability and accessibility of semolina in the ASW, Ondo State economy. Finally, the expenditure elasticity of semolina has the highest elasticity among the food items considered as necessity. Thus, the importance of semolina in ASW metropolis diet will increase as economic growth continues.

This study therefore recommends that effort should be made to boost economic activities of this zone. This will increase their income and consequently improve their spending on the nutritious food items. Secondly, government should work on improving the literacy level of the zone so that they would be able to identify and understand the nutritional implication of their food consumption and obtain a balanced diet from the limited available resources with them. Finally, the government should see the need to increase the standard of living for all, as this will boost the consumption pattern of all household in ASW metropolis as a whole.

\section{References}

Adejobi AO (2004). Rural poverty, food production and demand in Kebbi state, Nigeria, Unpublished Ph.D. Thesis, Department of Agricultural Economics, University of Ibadan. Unpublished.

Alston, J.M. \& J.A. Chalfant (1993). The silence of the lambdas: A test of the almost ideal and rotterdam models. American Journal of Agricultural Economics volume 75 304-13.

Baharumshah A.Z \& Mohamed Z.A (1993). Demand for meat in Malaysia: An application of the almost ideal demand system analysis, Pertanika Journal of Social Science and Humanities. 1(1), 91-95.

Bereket K, (2003). Intra-household distribution of expenditures in rural Ethiopia: A demand system approach, CSAE Working Paper Series 2003-08, Center For The Study Of African Economies, University Of Oxford.

Blanciforti, L.A., Green, R.D. \& King, G. A. (1986). US consumer behaviour over the postwar period: An almost ideal demand system analysis, Giannini Foundation, Monograph Series no. 40.

Central Bank of Nigeria (1996). Annual report and statement of accounts.

Deaton, A. J. \& Muellbauer, J. (1980). An almost ideal demand system. American Economics Review, 70: 312-326.

Fan, S., Wailes, E.J. \& Cramer, G.L. (1995). Household demand in rural China: A two-stage LES-AIDS Model. American Journal of Agricultural Economics, 77: 54-62.

Glewwe, Paul (2005). The impact of child health and nutrition on education in developing countries: Theory, econometric issues and recent empirical evidence. Food and Nutritional Bulletin (forthcoming).

Halbrendt, C., Tuan, F., Gempesaw, C. \& Dolk-Etz D. (1994). Rural Chinese Food Consumption: The Case of Guangdong. American Journal of Agricultural Economics. No. 76 pg 794799.

http://en.wikipedia.org/wiki/Akoko_South-West

Ishida, A., Law, S.-H. \& Aita, Y. (2003). Changes in food consumption expenditure in Malaysia. Agribusiness, 19: 6176. doi: 10.1002/agr.10038

Koutsoyiannis, A. (1982). Non-price decisions: The firm in a modern context, Macmillan, London.

Oyekale, S. A. (2000). An application of almost ideal demand systems (AIDS) to Food Demand in Nigeria. Nigeria Agricultural Development Studies, 1 (2), 43-52.

Sadoulet E \& de Janvry A (1995). Quantitative development policy analysis, Baltimore, John Hopkins University Press, 397.

USAID (1992). Food for peace Burkina Faso Food Security Country Framework FY 2010 - FY 2014. Washington, D.C 